\title{
Comparision between Low-Dose CT and Ultrasound in Diagnosis of Renal and Uretral Stones in Adults
}

\author{
DOAA N. ANAS, M.Sc.; KHALED I. ELSHAFEY, M.D.; HOSSAM M. ABDELHAFIZ, M.D. and \\ ALSHYMAA Z. ALSHAHAWY, M.D.
}

The Department of Radiology, Faculty of Medicine, Tanta University

\begin{abstract}
Background: Non-contrast computed tomography of the kidneys, ureters, and bladder (CT KUB) is the examination of decision for renal colic when compared to ultrasonography; be that as it may, radiation presentation can be a worry.

Aim of Study: Comparison between low dose CT and ultrasound in diagnosis of renal and uretral stones in adults.

Patients and Methods: This prospective study was conducted on fifty Egyptian adults meeting the inclusion criteria of hading flank pain, suspected to have urinary tract calculi and recruited from Urology Department of Tanta University to Radiology Department at Tanta University Hospitals. All patients were applied to careful history taken, clinical and laboratory examination then underwent imaging studies which include renal ultrasound examination and MDCT-KUB using low dose protocol. Each depicted stone was documented whether it is renal or uretric. All the stones were also defined as single or multiple, unilateral or bilateral and the maximum diameter of them. In case of upper urinary tract calculi reliable secondary signs of obstructing calculi were demonstrated. These include hydronephrosis, hydroureter, ipsilateral renal enlargement and ureter rim sign. The findings were confirmed by comparing to the previous standard CT scans that were done and detected in the medical records for 20 patients, uretroscopy in 12 patients, percutenous nephro lithotomy in 8 patients, medical treatment and more follow-up for 10 patients. The sensitivity, specificity and size accuracy of US was determined using low dose CT as the standard.
\end{abstract}

Results: Low dose CT showed number of renal and ureteral stones more than ultrasound with statistical significant $p$ value $<0.001$ with overall stones detected by ultrasound is 43 stones (5 ureteral and 38 renal) while low dose CT showed 96 stones (40 ureteral and 56 renal). The ultrasound missed 12 stones with $80 \%$ with mean size $4 \mathrm{~mm}$ at uretrovesical junction and 10 stones with $83.8 \%$ with mean size $6 \mathrm{~mm}$ at upper third of ureter. The ultrasound missed $100 \%$ of the ureteral stones in middle or distal ureter due to abdominal gases. The ultrasound overestimate the size in size group [4 to $10 \mathrm{~mm}$ ] by $3.3 \mathrm{~mm}$ with statistically significant $p$-value detected. The ultrasound sensitivity, specificity, accuracy for renal stones detection were $67.8 \%, 100 \%$ and $81.2 \%$ respec-

Correspondence to: Dr. Doaa N. Anas, The Department of Radiology, Faculty of Medicine, Tanta University tively when compared to low dose ct and the ultrasound sensitivity, specificity, accuracy for ureteral stones detection were $6.90 \%, 100 \%$ and $43.75 \%$ respectively when compared to low dose.

Conclusion: Low dose CT shows up as preferred imaging modality for uorolithiasis over ultrasound because of its high sensitivity and accuracy in identifying renal and ureteral stones.

Key Words: Uorolithiasis - Ultrasonography-Low dose CT.

\section{Introduction}

UROLITHIASIS is a standout amongst the most widely recognized issue of urinary tract.Imaging is significant for the analysis of acute and chronic urinary stones. Ultrasonography might be a satisfactory introductory examination in numerous cases, particularly in patients known to have a background marked by stones and in patients where radiation ought to be kept away from (e.g., pregnancy and children) [1]. In grown-ups, Unenhanced Multidetector (CT) has a high sensitivity $(95 \%$ $96 \%$ ) and specificity (97\%-100\%) for the conclusion of urinary stones, which was higher than intravenous urography or KUB. Be that as it may, concerning radiation dose, unenhanced $\mathrm{CT}$ has a higher danger of radiation peril than IVU or KUB, which may be a primary restriction of this examination. Exposure to limited quantities of radiation can cause malignant growth, particularly in younger patients [2].

Given the way that urinary stone is chronic in nature and requires continue imagingnormally utilizing CDCT, there might be a generous radiation dose during a person's lifetime. In this manner, there is a requirement for a precise analytic imaging tool with negligible radiation presentation. A meta analysis demonstrates the radiation portion for 
urinary stone $\mathrm{CT}$ acquisitions can be securely diminished beneath $3 \mathrm{mSv}$ without influencing the analytic exactness of stone recognition [2]. These days, the American Urological Association gives no reasonable recommendation [3], however the current rules of the American College of Radiology just as the European Association of Urology prompt utilizing low-do CT in patients with intense infection and doubt of urinary stone $[4,5]$

\section{Patients and Methods}

This prospective study was carried out on 50 Egyptian patients, clinically suspected to have urinary tract calculi referred from Urology Department and out clinics to the Department of Diagnostic Radiology Department in Tanta University hospitals for multi-slice CT examination from March 2017 to January 2019.

The commonest affected age group in our study was 41 to 60 years old as 20 patients were between 41 and 60 years old with $40 \%$ with mean age 49 years old. The male patients were 34 with $68.0 \%$ while the female patients were 16 with $32 \%$ with mean of 30.2 .

Inclusion criteria were: Adult patients with flank pain and suspected to have urinary tract calculi while exclusion criteria were: Pregnancy, age younger than 16 years old, body mass index $>40$ and inability to obtain informed consent.

An informed consent was obtained from all participants in this research after full explanation of the benefits and risks of the procedure. The participants in this study with flank pain and ordered to do renal CT scan were subjected to careful history was taken, clinical examination, laboratory investigations including: CBC, urine analysis (for detection of crystals, hematuria and urine $\mathrm{pH}$ ) then underwent imaging studies which include renal ultrasound examination and MDCT-KUB using low dose protocol.

The patients were told to prepare themselves carefully for the ultrasound scan by abstaining from food for the last 6 hours with continuous taking their drugs and ultrasound scan was carried out with the patient in supine position and additional scans in the lateral decubitus and prone were useful in some situations. Each depicted stone was documented whether it is renal or uretric, single or multiple, unilateral or bilateral and the maximum diameter of them.

Then MDCT-KUB using low dose is done without IV or oral contrast with fasting 8 hours prior the examination and full urinary bladder. Patients were placed in the supine position, head first with arm elevated above the head, with scanning range from $\mathrm{T} 12$ vertebra to the edge of pubic symphysis. Then the scans were performed with a 128 -section multidetector CT scanner (Optima HD 128-section; GE Healthcare), automatic tube current modulation scanning was used (a tube current range of 10-400 $\mathrm{mA}$ ) modified to be from $26 \mathrm{~mA}$ to $50 \mathrm{~mA}$ according to the body mass index of the patient, with noise index setting 25 in LDCT, and some other scanning parameters were as following: Gantry rotation time, 0.5 second; section thickness, $5 \mathrm{~mm}$; pitch, 1.375 , reconstruction interval $2.5 \mathrm{~mm}$ and table speed $17.5 \mathrm{~mm}$ per rotation.

Data were fed to the computer and analyzed using IBM SPSS software package version 20.0. (Armonk, NY: IBM Corp).

\section{Results}

The most common clinical presentation of the studied patients was flank pain as it appear in 46 patients with $92 \%$, followed by dysurea which appear in 12 patients with $24 \%$, hematuriea which have the same percentage as dysurea.

The overall stones detected by ultrasound is 43 stones (5 ureteral and 38 renal) while low dose CT showed 96 stones (40 ureteral and 56 renal). Low dose CT showed number of renal stones more than ultrasound with statistical significant $p$-value $<0.001$. Also low dose CT showed number of ureteral stones more than ultrasound with statistical significant $p$-value $<0.001$. The number of stones increased with the body mass index in ultrasound and low dose CT. The most common site for the detected ureteral stone was urterovesical (15 stones with $30 \%$ ).

The ultrasound overestimated the size in size group [0 to $4 \mathrm{~mm}$ ] by $1.8 \mathrm{~mm}$ with no statistically significant $p$-value detected, overestimated the size in size group [ 4 to $10 \mathrm{~mm}$ ] by $3.3 \mathrm{~mm}$ with statistically significant $p$-value detected and overestimated the size in size group [ $>10 \mathrm{~mm}$ ] by $1.5 \mathrm{~mm}$ with no statistically significant $p$-value detected. We found that stones classified as $5-10 \mathrm{~mm}$ by US had the highest probability (45\%) of having the management recommendation changed when a CT was performed.

The ultrasound sensitivity, specificity, accuracy for renal stones detection were $67.8 \%, 100 \%$ and $81.2 \%$ respectively when compared to low dose 
$\mathrm{CT}$ and the ultrasound sensitivity, specificity, accuracy for ureteral stones detection were $6.90 \%$, $100 \%$ and $43.75 \%$ respectively when compared to low dose CT.

\section{Discussion}

The aim of this study was to compare between the ultrasound and low dose CT in detecting urinary stones in adult patients.

Low dose CT appears as better imaging modality for urolithiasis than ultrasound due to its high sensitivity and accuracy in detecting renal and ureteral stones. Also it shows more accuracy in measuring stone size with reducing radiation exposure significantly than standard dose $\mathrm{CT}$ and cost acceptability as shown in Fig. (1). This study was conducted on fifty patients with commonest affected age group was 41 to 60 years old as 20 patients were between 41 and 60 years old with $40 \%$ which is approximately agree with (Vahlensieck EW, et al., 1982) [6] who studied a total of 10,130 individuals aged over 18 were interviewed to find out the incidence and prevalence of urolithiasis found that stone prevalence increased from $1.28 \%$ to $6.79 \%$ with increasing age. The male affection in our study was (34 patients) representing $68 \%$ which was more common than females ( 16 patients) representing $32 \%$. This is agree with (Shirazi F, et al., 2009) [7] who studied 161 patients with findings show that $66.5 \%$ of patients were male.

The most common clinical presentation of the studied patients was flank pain as it appear in 46 patients with $92 \%$. This agrees with (Spivacow FR, et al., 2010) [8] who studied a total of 160 patients and found that the most frequent form of presentation was renal colic (72\%). Nadeem M, et al., 2012 [9] studied 1550 patients and also stated that flank pain is the most common clinical presentation of urolithiasis.

In our study the overall stones detected by ultrasound is 43 stones ( 5 ureteral and 38 renal) while low dose CT showed 96 stones (40 ureteral and 56 renal) as shown in (Table 1). This agree with (Oner S, et al., 2004) [10] who studied 29 patients and found that CT detected 57 stones (45 renal and 12 ureteral) while US detected 34 stones. Ganesan V, et al., 2017 [11] also studied 486 patients with both ultrasound and CT scans showed that CT detected a significantly greater number of stones: 299 vs. 184 on US ( $p<0.001)$.
Table (1): Descriptive analysis of the studied cases according to number of stones $(\mathrm{n}=50)$.

\begin{tabular}{lll}
\hline & \multicolumn{1}{c}{ US } & Low dose CT \\
\hline $\begin{array}{l}\text { Number of ureteral stones: } \\
\quad\end{array}$ & $0.0-1.0$ & $0.0-3.0$ \\
$\quad$ Min.-max. & $0.80 \pm 0.27$ & $0.80 \pm 0.70$ \\
Mean \pm SD. & 5.0 & 40.0 \\
$\quad$ Total & & \\
Number of kidney stones: & & \\
$\quad$ Min.-max. & $0.0-3.0$ & $0.0-5.0$ \\
Mean \pm SD. & $0.76 \pm 0.96$ & $1.12 \pm 1.29$ \\
$\quad$ Total & 38.0 & 56.0 \\
Number of ureteral \& & & \\
kidney stones: & & \\
$\quad$ Min.-max. & & \\
$\quad$ Mean \pm SD. & $0.0-3.0$ & $1.0-5.0$ \\
Total & $0.84 \pm 0.93$ & $1.92 \pm 1.21$ \\
& 43.0 & 96.0 \\
\hline
\end{tabular}

Low dose CT showed number of renal stones more than ultrasound with statistical significant $p$ value $<0.001$. This agree with (Ather $\mathrm{MH}$, et al., 2004) [12] who studied 864 patients which had unenhanced helical CT for evaluation of the urinary tract with out of these 34 patients had both UHCT and US, UHCT identified renal stones in $21(62 \%)$, whereas 17 of these were identified on US. Also (Oner S, et al., 2004) [10] studied 29 patients with spiral CT showed 45 stones in 28 kidneys while US was able to localize 31 stones $(68,9 \%, 31 / 45)$ in 21 kidneys.

Low dose CT showed number of ureteral stones more than ultrasound with statistical significant $p$ value $<0.001$. This agree with (Oner $S$, et al., 2004) [10] who studied 29 patients and found that ultrasound could identify 3 stones (25\%) in 11 ureters while CT showed 12 stones in 11 ureter and difference between US and CT rates of renal and ureteral stone detection was significant (chi-square, $p<0.05$ ). Also this agree with (Ather MH, et al., 2004) [12] who studied 864 patients which had UHCT for evaluation of the urinary tract with out of these 22 patients with ureteric stone, on UHCT, US could only identify 10 . Twelve patients with ureteric stones identified on UHCT were missed on US.

In the current study we found that the number of stones increased with the body mass index in ultrasound and low dose CT as shown in Fig. (2). This is agree with (Shrivastava SK, et al., 2016) [13] who studied a total of 100 patients who underwent open surgical procedures for urolithiasis and found that $68 \%$ of subjects had BMI more than normal supporting the evidence that renal stone disease is more common in higher BMI patients. 
The most common site for the detected ureteral stone was uterovesical (15 stones with $30 \%$ ) then proximal ureter ( 12 stones with $24 \%$ ) then distal ureter ( 8 stones with $16 \%$ ) then middle ureter (5 stones with $10 \%)$. This approximately agrees with (Souza LR, et al., 2007) [14] who studied 52 consecutive patients and found that the locations of the calculi were: UVJ (47\%), proximal (30\%), distal (18\%) and mid-ureteral $(5 \%)$.

Table (2): Stone size measured by ultrasonography compared with CT.

\begin{tabular}{llllll}
\hline Size $(\mathrm{mm})$ & Size on CT & Size on US & Difference US-CT & \multicolumn{1}{c}{ Z } & \multicolumn{1}{c}{$p$} \\
\hline $0-4$ & $2.5(3.0-8.0)$ & $5.5(2.0-3.4)$ & $2.5(-1.0-3.4)$ & 1.857 & 0.063 \\
$5-10$ & $8.0(7.5-11.5)$ & $9(6.0-10.0)$ & $6.0(-1.0-8.0)$ & $3.335^{*}$ & 0.001 \\
$>10$ & $14.0(9.0-20.0)$ & $15(12.0-19.3)$ & $11.50(-1.5-13.8)$ & 1.536 & 0.124 \\
\hline
\end{tabular}

Stones were grouped, based on the longest axis diameter, into three categories according to clinical relevance in management: $<4 \mathrm{~mm}$ (where observation would probably be recommended), $5-10 \mathrm{~mm}$ (where shockwave lithotripsy would probably be recommended) or $>10 \mathrm{~mm}$ (where an endoscopic approach would probably be recommended). These groupings were based on previously reported practice patterns [15]. Analyses of size of stones on US were calculated using CT as the standard reference. In our study we found that ultrasound overestimate the size in size group [0 to $4 \mathrm{~mm}$ ] by $1.8 \mathrm{~mm}$ with no statistically significant $p$-value detected. The ultrasound overestimate the size in size group [4 to $10 \mathrm{~mm}$ ] by $3.3 \mathrm{~mm}$ with statistically significant $p$-value detected. Also we found that the ultrasound overestimate the size in size group [ $\geq 10 \mathrm{~mm}$ ] by $1.5 \mathrm{~mm}$ with no statistically significant $p$-value detected as shown in (Table 2). This agree with (Ganesan V, et al., 2017) [11] at two points and disagree at one point as they studied 486 patients with both ultrasound and CT scans showed that US overestimated stone sizes for size groups 0$4 \mathrm{~mm}$ and $5-10 \mathrm{~mm}$ with statistically significant $p$ value $(p<0.001)$. There was no significant difference for stones $>10 \mathrm{~mm}$. Also, (Sternberg KM, et al., 2016) [16] who studied 155 patients received both a renal US and NCCT within 1 day stated that US overestimated stone size by $2.2 \mathrm{~mm}(p<0.001)$.

Because stone size measurements affect counseling decisions, we found that stones classified as $5-10 \mathrm{~mm}$ by US had the highest probability
(45\%) of having the management recommendation changed when a CT was performed. This agree with Ganesan V, et al., 2017 [11] who studied 486 patients and found that stones classified as $5-10 \mathrm{~mm}$ by US had the highest probability (43\%) of having the management recommendation changed when a CT was performed.

A wide range of sensitivities and specificities for ultrasonography have been reported, probably owing to variations in technique, body habitus, patient population and reference standards. Imaging stones in the renal pelvis and in the ureter also present different challenges as it is difficult to image the length of an undilated ureter owing to interference by bowel gas and increased penetration depth. In this study the ultrasound sensitivity, specificity, accuracy for renal stones detection were $67.8 \%, 100 \%$ and $81.2 \%$ respectively when compared to low dose CT. This agrees with (Ather MH, et al., 2004) [12] who studied 864 patients stated that US is sensitive and specific for renal stones, $81 \%$ and $100 \%$. Also (Sharma S, et al., 2018) [17] who studied 136 patients and stated that ultrasound sensitivity is $80-84 \%$ and ultrasound specificity is $50-53 \%$. This study showed that the ultrasound sensitivity, specificity, accuracy for ureteral stones detection were $6.90 \%, 100 \%$ and $43.75 \%$ respectively when compared to low dose CT. This approximately agrees with (Souza LR, et al., 2007) [14] who studied 52 consecutive patients and found that US presented sensitivity of $22 \%$ and specificity of $100 \%$.

Table (3): Agreement (sensitivity, specificity and accuracy) for number of kidney and ureteral stones $(n=96)$.

\begin{tabular}{lccccc}
\hline & Sensitivity & Specificity & PPV & \multicolumn{2}{c}{ NPV Accuracy } \\
\hline US/number of kidney & 67.86 & 100.0 & 100.0 & 68.97 & 81.25 \\
US/ureteral stones & 6.90 & 100.0 & 100.0 & 41.30 & 43.75 \\
\hline
\end{tabular}

\section{Conclusion:}

Low dose CT appears is better imaging modality for uorolithiasis than ultrasound due to its high sensitivity and accuracy in detecting renal and ureteral stones. Also it shows more accuracy in measuring stone size with reducing radiation exposure significantly and cost acceptability. 


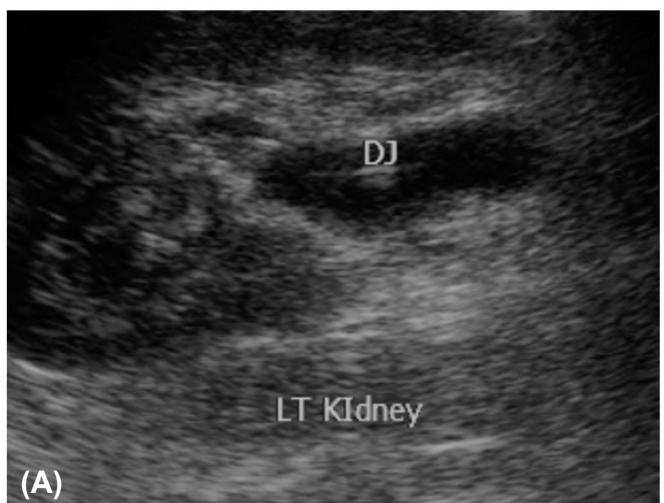

Ultrasound of right kidney

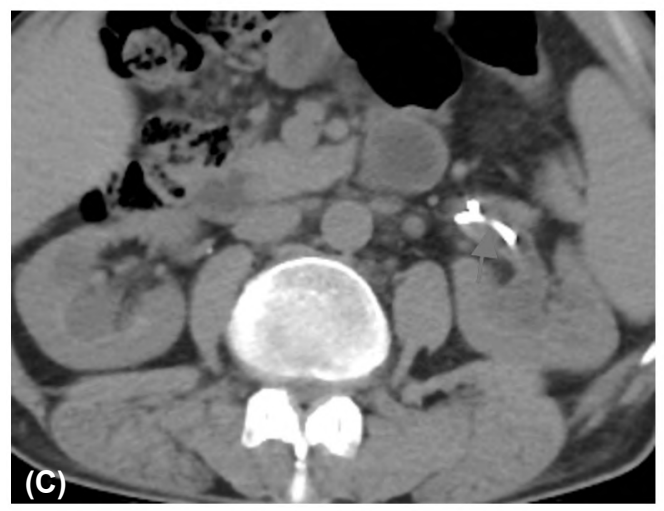

Axial non-contrast standard dose (160ma) CT reformatted by MPR

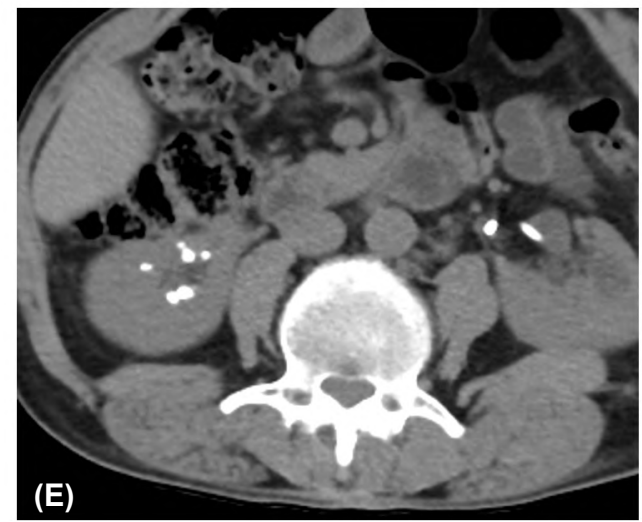

Axial non-contrast standard dose (160ma) CT reformatted by MPR

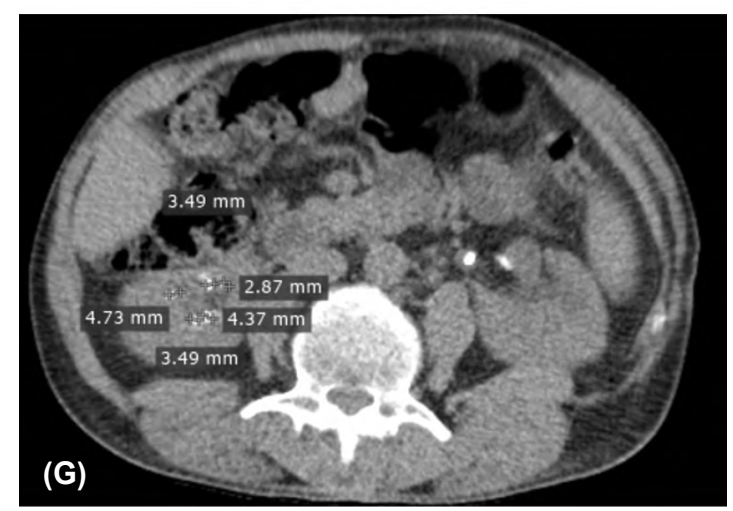

Axial non-contrast low dose (26ma) CT reformatted by MPR

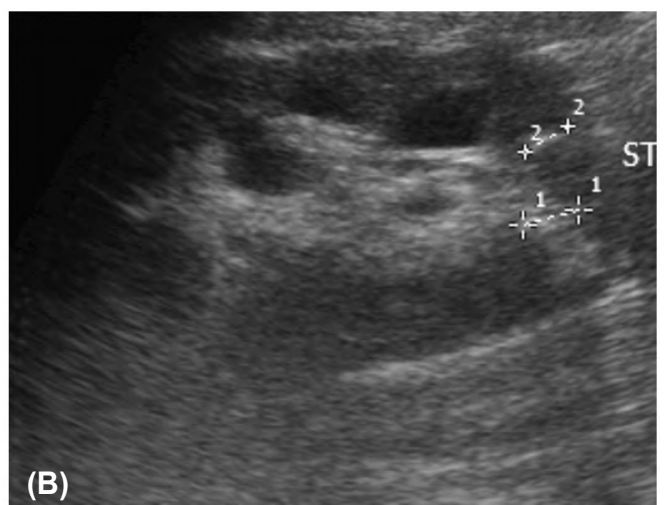

Ultrasound of left kidney

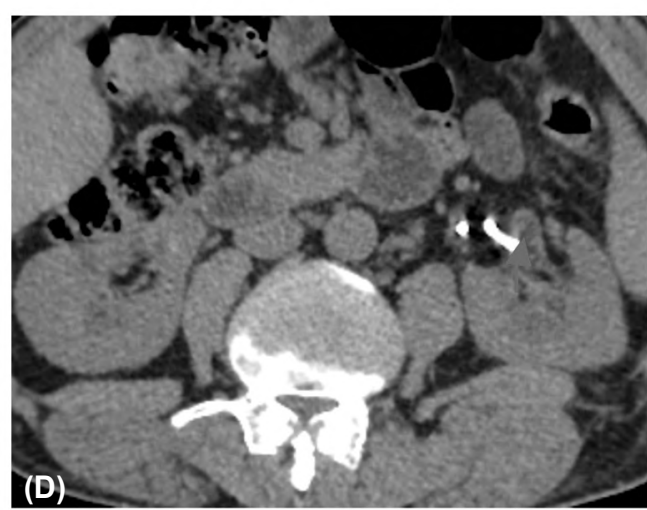

Axial non-contrast low dose (26ma) CT reformatted by MPR

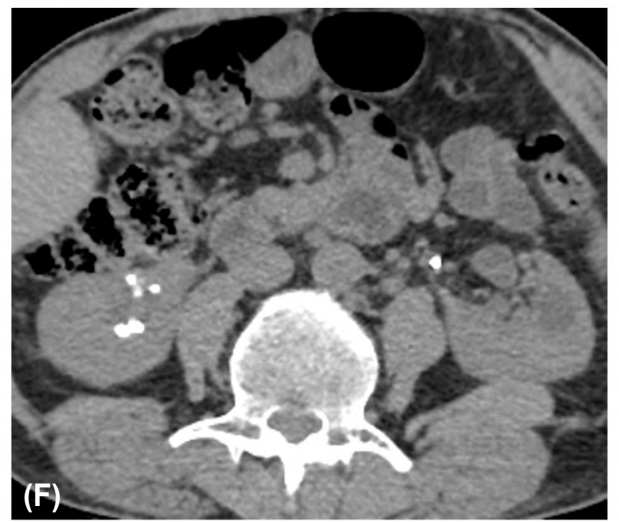

Axial non-contrast low dose (26ma) CT reformatted by MPR

Fig. (1): A male patient aged 57 years old weighted $80 \mathrm{~kg}$, with left renal J-stent and previous standard CT presented clinically with bilateral flank pain more pronounced in right side and hematuria. (A) Shows two hyperechoic stones measuring $7 \mathrm{~mm}$ and $6 \mathrm{~mm}$ with mild hydronephrosis in right kidney. (B) Shows hyper-echoic Jstent with mild hydronephrosis in left kidney. (C,D) Show left renal J-stent with standard and low dose CT. (E,F) Show five hyper-dense stones in right kidney in standard with the same at low dose CT. G) Shows the measurements of stones in low dose CT [2.8, 3.4, 3.5, 4.3, 4.7mm]. 

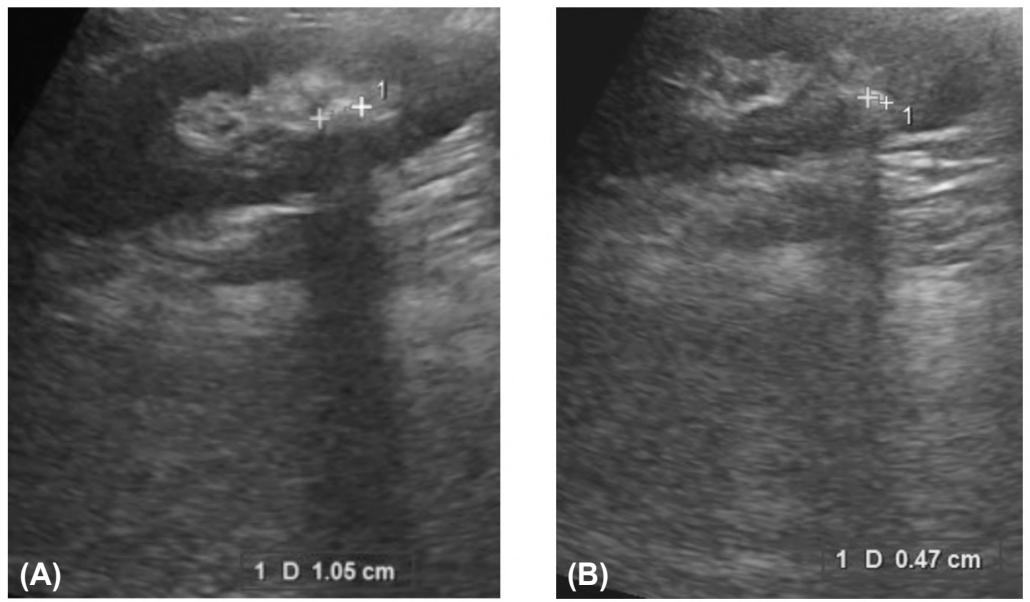

Ultrasound of right kidney

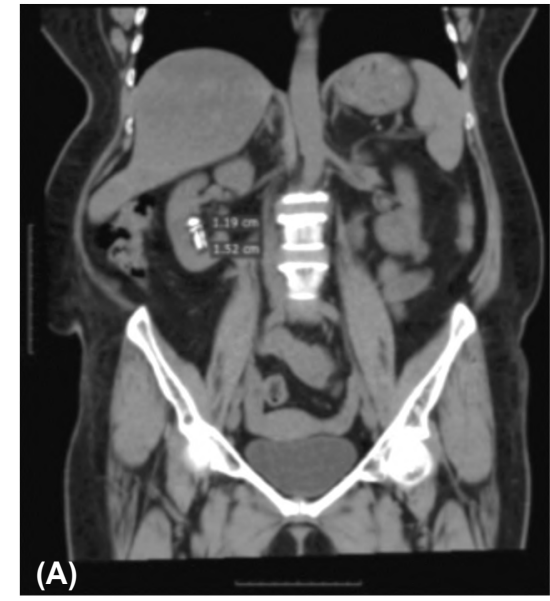

Curved coronal non-contrast standard dose (300ma) CT reformatted by MPR

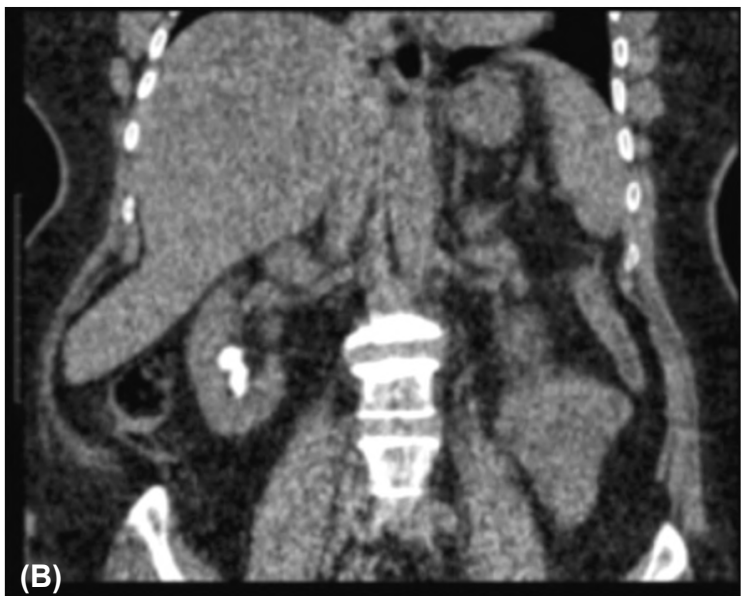

Curved coronal non-contrast low dose (36ma) CT reformatted by MPR

Fig . (2): A Female patient aged 56 years old weighted $113 \mathrm{~kg}$, have previous standard CT, presented clinically with right flank pain. (A\&B) Show two hyper-echoic stones measuring 10 and $4 \mathrm{~mm}$ in right kidney. (C\&D) Show two hyper-dens stones measuring 11 and 5mm in standard (300ma) CT and low dose (36ma) CT.

\section{References}

1- CHANG I.H., KIM J.W., MYUNG S.C., KIM T.H., MOON Y.T., KIM K.D., AHN S.H., KIM J.H., LEE S.Y., KIM M.S. and CHI B.H.: Low-dose unenhanced computed tomography with iterative reconstruction is available for the diagnosis of urinary stones. European Urology Supplements, 31; 17 (2): e918, 2018.

2- NIEMANN T., KOLLMANN T. and BONGARTZ G. Diagnostic performance of low-dose CT for the detection of urolithiasis: A meta-analysis. A.J.R. Am. J. Roentgenol., 191: 396-401, 2008.

3- PEARLE M.S., GOLDFARB D.S., ASSIMOS D.G., CURHAN G., DENU-CIOCCA C.J., MATLAGA B.R., MONGA M., PENNISTON K.L., PREMINGER G.M., TURK T.M. and WHITE J.R.: Medical management of kidney stones: AUA guideline. J. Urol., 192: 316-24, 2014.

4- COURSEY C.A., CASALINO D.D., REMER E.M., ARELLANO R.S., BISHOFF J.T., DIGHE M., FULGHAM P., GOLDFARB S., ISRAEL G.M., LAZARUS E. and LEYENDECKER J.R.: ACR Appropriateness
Criteria ${ }^{\circledR}$ acute onset flank pain-suspicion of stone disease. Ultrasound Quarterly, 1; 28 (3): 227-33, 2012.

5- TÜRK C., PETRÍK A., SARICA K., SEITZ C., SKOLARIKOS A., STRAUB M. and KNOLL T.: EAU guidelines on diagnosis and conservative management of urolithiasis. European urology, 1; 69 (3): 468-74, 2016.

6- VAHLENSIECK E.W., BACH D. and HESSE A.: Incidence, prevalence and mortality of urolithiasis in the German Federal Republic. Urological research, 1; 10 (4): 161-4, 1982.

7- SHIRAZI F., SHAHPOURIAN F., KHACHIAN A., HOSSEINI F., HEIDARI S. and SANJARI M.: Personal characteristics and urinary stones. Hong Kong Journal of Nephrology, 1; 11 (1): 14-9, 2009.

8- SPIVACOW F.R., NEGRI A.L., DEL VALLE E.E., CALVIÑO I. and ZANCHETTA J.R.: Clinical and metabolic risk factor evaluation in young adults with kidney stones. International Urology and Nephrology, 1; 42 (2): 471-5, 2010. 
9- NADEEM M., ATHER M.H., JAMSHAID A., ZAIGHAM S., MIRZA R. and SALAM B.: Rationale use of unenhanced multi-detector CT (CT KUB) in evaluation of suspectedrenal colic, Int. J. Surg., 10: 634-7, 2012.

10- ONER S., OTO A., TEKGUL S., KOROGLU M., HASCICEK M., SAHIN A. and AKHAN O.: Comparison of spiral CT and US in the evaluation of pediatric urolithiasis. JBRBTR: Organe de la Societeroyalebelge de radiologie (SRBR) organe van de Koninklijke Belgische Verenigingvoor Radiologie (KBVR), 87 (5): 219-23, 2004.

11- GANESAN V., De S., GREENE D., TORRICELLI F.C and MONGA M.: Accuracy of ultrasonography for renal stone detection and size determination: Is it good enough for management decisions? Bju International, 119 (3): 464-9, 2017.

12- ATHER M.H., JAFRI A.H. and SULAIMAN M.N.: Diagnostic accuracy of ultrasonography compared to unenhanced CT for stone and obstruction in patients with renal failure. BMC Medical Imaging, 4 (1): 2, 2004.

13- SHRIVASTAVA S.K., SONGRA M.C. and JAIN R.: Association of body mass index, urinary $\mathrm{pH}$ and urolithiasis. International Surgery Journal, 9; 3 (3): 1598-602, 2016.
14- SOUZA L.R., GOLDMAN S.M., FAINTUCH S., FARIA J.F., BEKHOR D., TIFERES D.A., ORTIZ V., CHOYKE P. and SZEJNFELD J.: Comparison between ultrasound and noncontrasthelical computed tomography for identification of acute ureterolithiasis in a teaching hospital setting. Sao Paulo Medical Journal, 125 (2): 102-7, 2007.

15- EGE G., AKMAN H., KUZUCU K. and YILDIZ S.: Acute ureterolithiasis: Incidence of secondary signs on unenhanced helical CT and influence on patient management. Clin. Radiol., 58 (12): 9904, 2003.

16- STERNBERG K.M., EISNER B., LARSON T., HAN J., HERNANDEZ N. and PAIS V.M.: Ultrasonography Significantly Overestimates Stone Size When Compared to Low-Dose Non-Contrast Computed Tomography. Urology, 8; 95: 67-71, 2016.

17- SHARMA S., CHAUDHARI R., RAWAL K. and KHANT S.: Low dose computed tomography KUB region for management of urolithiasis in Indian scenario. International Surgery Journal, Jan. 25; 5 (2): 638-42, 2018.

18- INGIMARSSON J.P., KRAMBECK A.E. and PAIS V.M.: Diagnosis and Management of Nephrolithiasis. Surgical Clinics of North America, 30; 96 (3): 517-32, 2016.

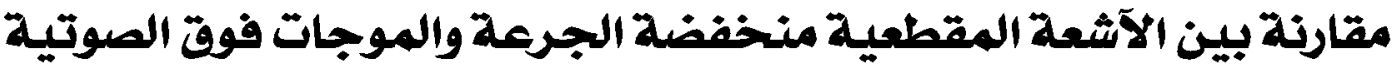

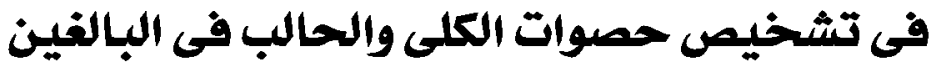

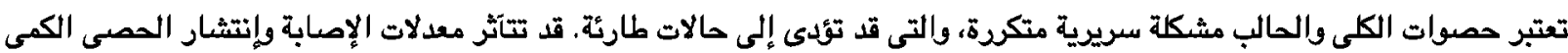

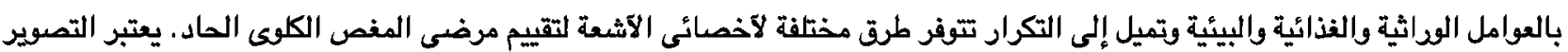

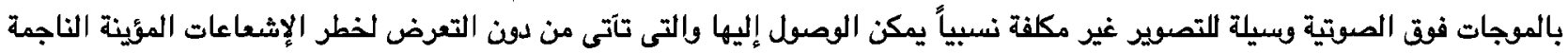

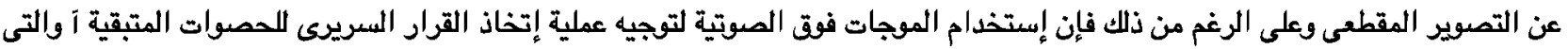

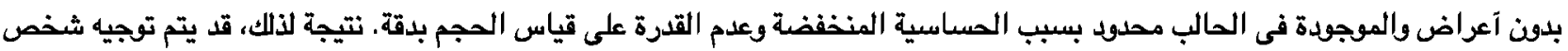

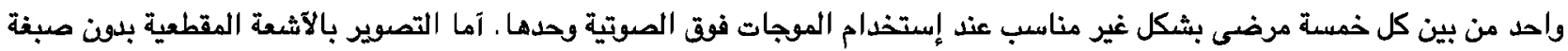

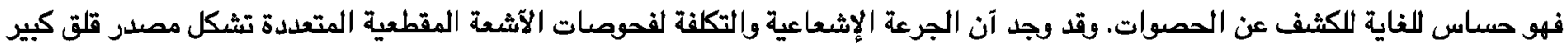

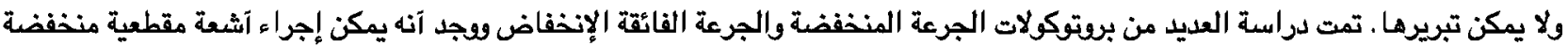

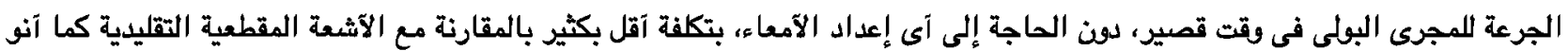

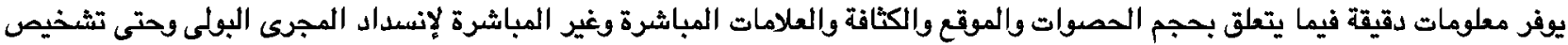
الحالات غير المسالك البولية. 